\title{
Sharing of Teaching Strategies in Pharmacology for Medical Undergraduates
}

\author{
Feng Gao*, Yanxiang Li*, Linlin Wang, Ruiyan Pan, Zhipeng Sun, Jinhong Wang\# \\ Department of Pharmacology, School of Pharmacy, Weifang Medical University, Weifang, China \\ Email: "wfmcwjh@wfmc.edu.cn
}

How to cite this paper: Gao, F., Li, Y. X., Wang, L. L., Pan, R. Y., Sun, Z. P., \& Wang, J. H. (2021). Sharing of Teaching Strategies in Pharmacology for Medical Undergraduates. Creative Education, 12, 2846-2851. https://doi.org/10.4236/ce.2021.1212211

Received: November 12, 2021

Accepted: December 17, 2021

Published: December 20, 2021

Copyright $\odot 2021$ by author(s) and Scientific Research Publishing Inc. This work is licensed under the Creative Commons Attribution International License (CC BY 4.0).

http://creativecommons.org/licenses/by/4.0/ (c) (i) Open Access

\begin{abstract}
According to the characteristics of pharmacology course, the teaching strategies for medical undergraduates were shared from the angle of dealing with the key and difficult contents. During the offline classroom teaching, forming an overall outline was focused, the impression of key drugs was deepened, the main line of content was clarified, and a total-separate-total structure was used. Part of the content was presented with the help of online teaching resource and software. Also the after-school teaching evaluation and feedback should be considered seriously. All the above strategies will finally get better results in teaching.
\end{abstract}

\section{Keywords}

Pharmacology, Medical Undergraduates, Key Content, Difficult Content, Offline Teaching

\section{Introduction}

Pharmacology is a discipline originated from activities to identify therapeutics from natural products (Winquist, Mullane, \& Williams, 2014). Medical undergraduates study the course after basic disciplines and before clinical disciplines. But students have not studied clinical disciplines such as internal science and surgery, and the learning effect of students is limited. In addition, content saturation, course placement and resources may be barriers to learning pharmacology for undergraduates (Foster, Collins, Dong, Nteff, \& Pinkney, 2017). Furthermore, new educational insights and scientific developments in pharmacology research inspire teachers to regularly rethink and adjust teaching strategies (Engels, 2018). In this study, we discussed the characteristics of pharmacology ${ }^{*}$ Gao Feng and Li Yanxiang contributed equally to this work.

\#Corresponding author. 
course, some teaching strategies, and full application of online resources after class, as well as the feedback of after class. In order to improve the teaching quality, we have explored strategies to clarify key and difficult problems in pharmacology, which are shared as follows.

\section{Characteristics of Pharmacology Course}

The pharmacologic effect and mechanism of drugs will be studied in pharmacology to guide clinical rational drug therapy. Therefore, to understand drugs well, high requirements for students' understanding and practical ability are essential. Complexity of pharmacology is present in the following aspects: 1) Nearly 600 classic drugs were showed in Chinese textbooks. Students often make mistakes, such as ampicillin and amoxicillin; 2) So many pharmacological effects of one drug, such as atropine affects many tissues and organs; 3) Incomprehensible mechanism of action, such as antibiotics and antitumor drugs; 4) Obvious different role in therapeutic uses although the pharmacological effects are similar, such as epinephrine and norepinephrine. Therefore, a large number of medical undergraduates encountered difficulties in learning and application of drugs studied in pharmacology over the past many years. In order to make students understand the drugs more clearly and easily and get a better teaching result, it's better for every professional teacher to explore teaching skills constantly.

\section{Teaching Strategies in Classroom}

\subsection{Sorting the Contents of Textbooks-Forming an Overall Outline}

The first lesson played an important role in pharmacology teaching. In the first lesson, students needed to understand the framework of pharmacology, clarify the contents to be learned and the internal relationship between each chapter. Pharmacology was described as a tree in our class. The large branches of the tree represented 7 modules of pharmacology: principles of drug therapy, autonomic nervous system drugs, central nervous system drugs, cardiovascular and visceral system drugs, endocrine system drugs and chemotherapeutic drugs. The leaves were the specific chapter in each system, and the interaction of leaves meant there would be complex interrelationship among chapters (see Figure 1). Therefrom students understood the content of pharmacology from the whole to the part to avoid disrupt the main content of pharmacology.

\subsection{Exhibition of Key Points-Deepening Drug Impression}

The course introduction played an important role in key drugs teaching. When learning a new chapter, the following ways of introduction usually used: firstly, introduction from a basic medical knowledge review, such as introduction of adrenoceptor agonists from the performance of sympathetic excitation; Secondly, introduction from clinical cases, such as introduction of antipyretic from the symptoms of cold patients; The third, it was introduced from well-known adverse 


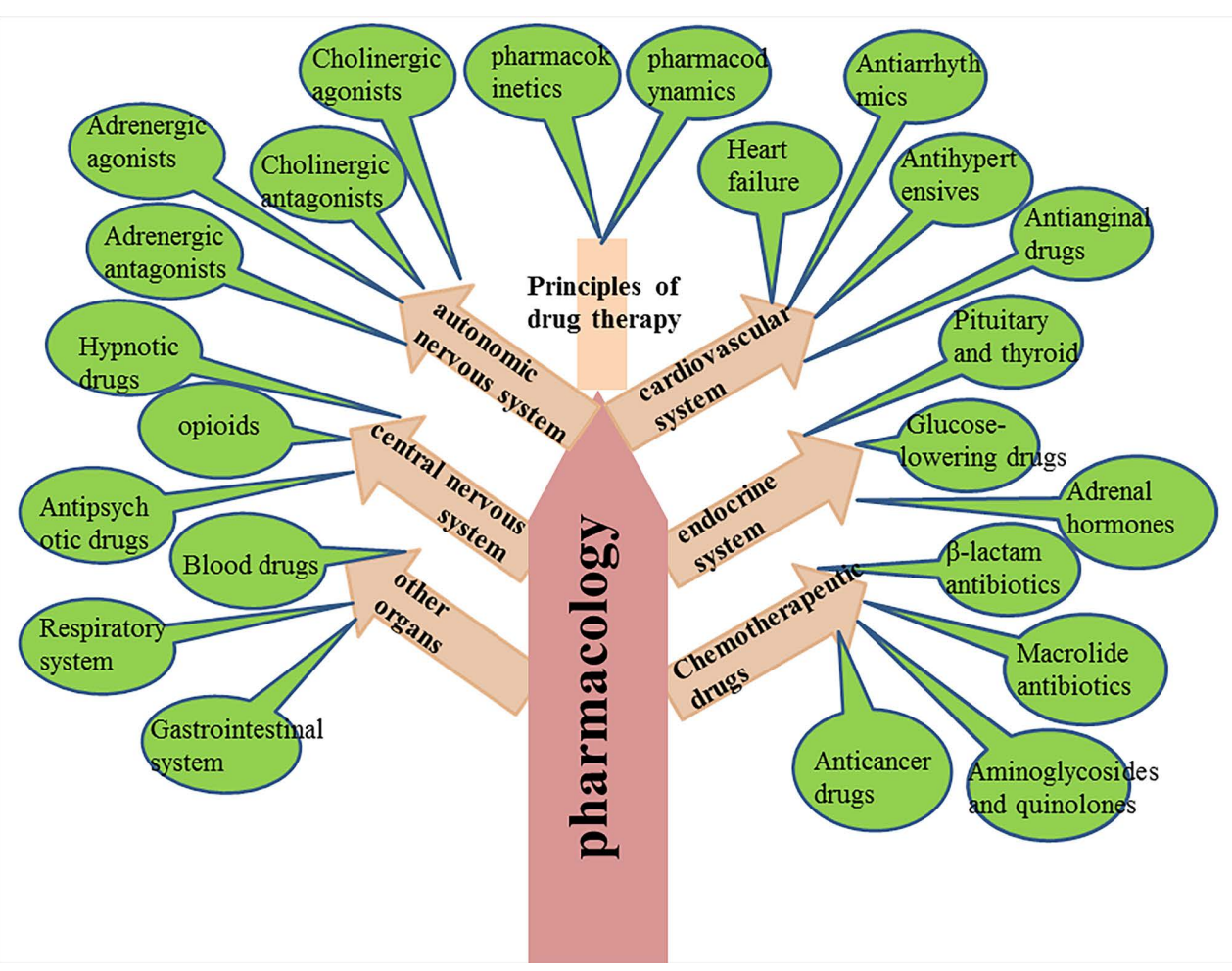

Figure 1. General framework of pharmacology: the whole to the part.

drug reactions, such as a case of penicillin anaphylactic shock led to $\beta$-Lactam antibiotics; The fourth method was use of props, such as one bottle of captopril tablets led to antihypertensive drugs. In the teaching of medical courses, teachers carrying useful props may receive unexpected effects.

During teaching, it was better to spend longer time on explaining key drugs. For example, chapter "choline receptor blockers" was arranged for 1.5 class hours (70 minutes), and about 45 minutes was used to study the key drug named atropine, while the explanation of scopolamine may be only 3 minutes to $5 \mathrm{mi}$ nutes. So, students were impressed by long-time study and repeated reminds of key drugs.

In the explanation of key drugs, it was better to make full use of multimedia. Teaching method as questioning teaching, case teaching and comparative teaching was usually applied according to the teaching content and situation in class. So the teacher can activate the classroom atmosphere, also improve student understanding and oral expression ability (Nayak, Sridevi, Sahu, Nagendra, Telang, Goudappala, \& Chandrakanth, 2021).

\subsection{Simplification of Difficulties in the Course-Clarifying the Main Line}

For difficult problems, different methods were used according to different situation. The elaboration of abstract concepts and phenomena could be popularized through appropriate examples. When explain the distinction between "quantitative response" and "qualitative response", three students demonstrated. One 
student had $¥ 1$, and the second one had $¥ 10$, this was quantitative response. Another student had no money (¥0), compared with the two students just mentioned, this was a qualitative reaction. Then the students understood it easily. The display of drug action mechanism was better in intuitive ways as graph, table and animation. For example, when study the action mechanism of antiarrhythmic drugs, students must review the normal myocardial electrophysiology in physiology before beginning of this part. In class, electrophysiological maps and ion flow animation were used to show cardiac electrical situation. Questioning teaching was adopted here. If an abnormal part occurred, please explain the possible disease that would happen, then analyse the method to treat the disease. During the process of review and questioning, mechanism of antiarrhythmics understood by the students easily.

\subsection{Summary of the Course-Return to the Overall Framework}

The first lesson was the key of pharmacology teaching, and the last lesson became an echo of the first lesson. At the end of the course, the overall outline of the course should be sorted, and the separated chapters and modules be integrated to form a coherent whole, which can be displayed and summarized with a tree diagram (see Figure 2).

\section{Full Application of Online Resources after Class}

Teaching in undergraduate classroom should pay attention to inspire students'
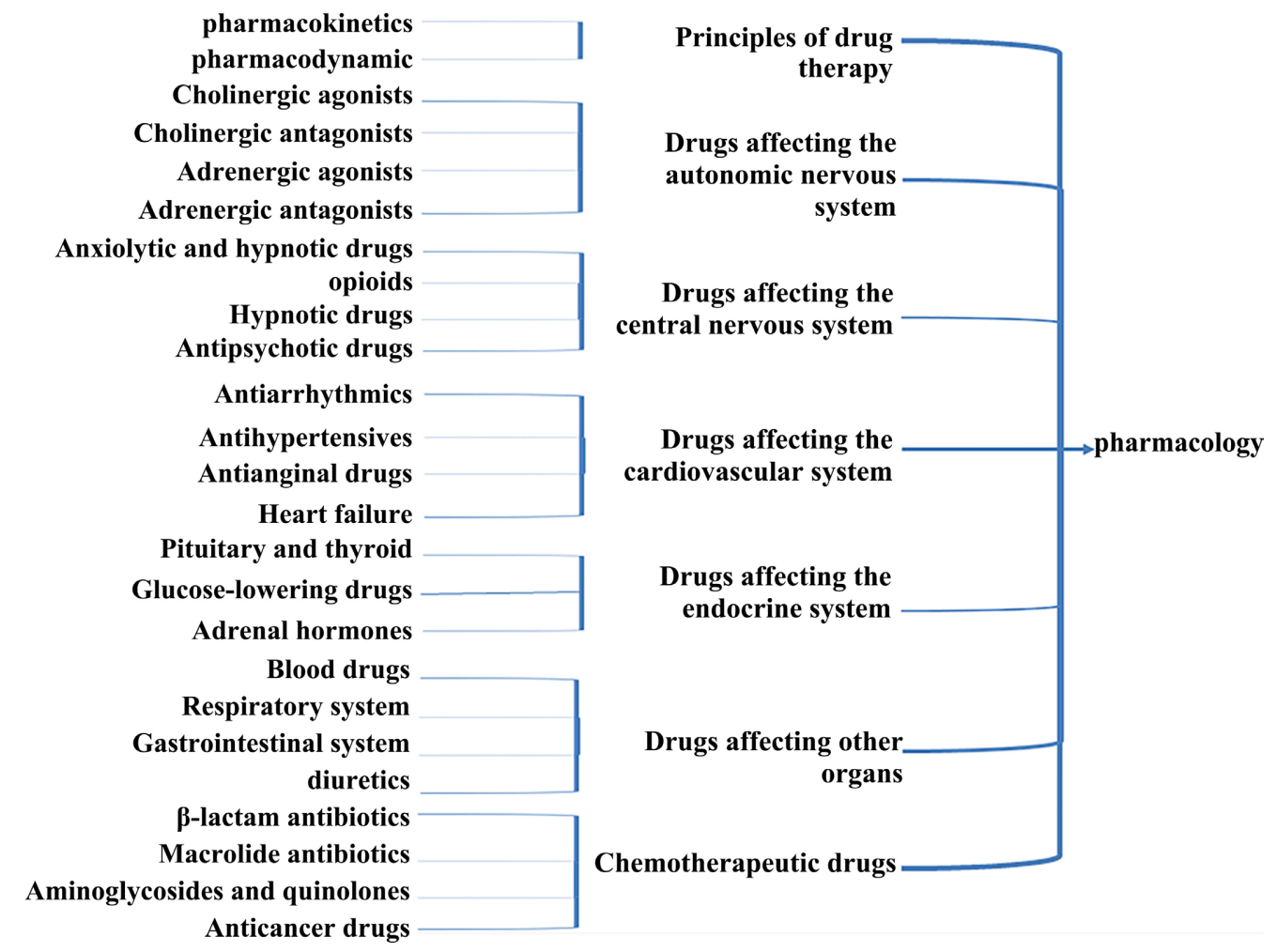

Figure 2. Summary of pharmacology: the part to the whole. 
interest in autonomous learning and the ability to explore problems. The improvement of these abilities depends on classroom time alone was obviously insufficient. Based on the previous offline teaching and guidance, integrating the advantages of traditional learning and digital learning, with full and rational use of online resources, is undoubtedly a very good solution. It has been reported that learning outcomes in an online course was the same as that of traditional students (Stack, 2015). Furthermore, the online learning perceived potential to provide more flexible access to content and instruction.

In recent years, a large number of intelligent teaching platforms had emerged one after another. The main public service platforms of online open courses in China include: massive open online course (MOOC), zhihuishu

(https://www.zhihuishu.com/), open course of NETEASE (https://open.163.com/), rain classroom (https://www.yuketang.cn/), etc. (Jiang \& Qu, 2021). The advantages of above teaching platform are obvious: firstly, the learning content is rich and diverse. Software zhihuishu, for example, is used in pharmacology teaching in our school. It includes videos for students to learn after class, training question bank and homework examination for learning effect test, learning resources for students to expand knowledge, and others; secondly, there are various ways to consolidate knowledge.

\section{Feedback of after Class Teaching Evaluation}

When evaluating the effect of teaching reform, the students' examination results were not the only index that be analyzed. Feedback of the evaluation of students and peer teachers also should be analyzed. It included two aspects: firstly, let students freely judge the advantages and disadvantages of the teaching reform in study key points and difficulties compared with the previous simple explanation in class. Students evaluated and put forward suggestions through anonymous questionnaire. Then teaching mode that got high acceptance was retained, the teaching deficiencies with low evaluation according to the results of students' evaluation and suggestions were improved; secondly, fully understood the evaluation from teaching supervision experts and peer teachers in the school, especially suggestions from the supervision experts. The experts had rich teaching experience and could give guidance and suggestions on the problems and deficiencies existing in the teaching process from a higher perspective. Therefore, the advantages and disadvantages of pharmacology teaching mode exploration were examined from the perspectives of students + experts + peer teachers, and the teaching effect was gradually improved.

Full application of online resources for future teaching and training practices is also needed. Students can use homework examination, review slide from teacher. Correct application of class group chat can greatly improve the effect of interaction with students and help them to understand the content. According to the teaching objectives and classroom teaching situation, the instructor can also record short videos with mobile phones to explain the difficult problems that 
many students ask questions. The above intelligent teaching software each has its own advantages. The key problem needed to solve next is how to improve students' interest in learning by using software.

Through analysis of study results after dealing with the details of the teaching process in pharmacology teaching, we believe that if teachers with open mind and courage to innovate can put in time and energy on key problems, make breakthroughs in difficult problems, pay attention to improving students' interest in learning, explore and study teaching skills constantly, better results in course teaching will eventually achieved.

\section{Fund}

This work was supported by Teaching reform project of Weifang Medical University (2019YB026) and Industry university cooperation collaborative education project of the Ministry of Education (202101339005).

\section{Conflicts of Interest}

The authors declare no conflicts of interest regarding the publication of this paper.

\section{References}

Engels, F. (2018). Pharmacology Education: Reflections and Challenges. European Journal of Pharmacology, 833, 392-395. https://doi.org/10.1016/j.ejphar.2018.06.032

Foster, V., Collins, E., Dong, H., Nteff, G., \& Pinkney, L. (2017). Teaching Clinical Pharmacology to Undergraduate Nursing Students: Barriers and Strategies. Open Journal of Nursing, 7, 918-929. https://doi.org/10.4236/ojn.2017.78068

Jiang, H., \& Qu, P. (2021). The Development for Application of Massive Open Online Course in Clinical Medicine Teaching. China Continuing Medical Education, 13, 77-81.

Nayak, B. S., Sridevi, V., Sahu, P. K., Nagendra, S., Telang, L., Goudappala, P., \& Chandrakanth, H. K. (2021). Students' Engagement and Perceptions of Small Group Tutorial Classes among Undergraduate Medical Students. Journal of Advances in Medical Education \& Professionalism, 9, 18-25.

Stack, S. (2015). Learning Outcomes in an Online vs Traditional Course. International Journal for the Scholarship of Teaching and Learning, 9, Article 5.

https://doi.org/10.20429/ijsotl.2015.090105

Winquist, R. J., Mullane, K., \& Williams, M. (2014). The Fall and Rise of Pharmacology(Re-)defining the Discipline? Biochemical Pharmacology, 87, 4-24.

https://doi.org/10.1016/j.bcp.2013.09.011 